\title{
Programa de Complementação de Renda Bolsa-Família: política de Estado ou política de governo?
}

Adriana Fonseca de Azevedo - Doutora em Serviço Social pela UFRJ, membro do Programa de Pós-Graduação em Desenvolvimento Sustentável do Trópico Úmido (PDTU) do NAEA e do Programa de Pós-Graduação em Serviço Social da UFPA.

\section{Resumo}

Este artigo apresenta uma avaliação política da concepção e da formulação de uma política social, cuja estratégia prioritária são os programas de transferência monetária. Nesse sentido, esta pesquisa objetiva explicitar o delineamento de uma política de renda mínima no Brasil e toma como referência o processo de unificação dos programas de garantia de renda existentes na realidade brasileira em torno do programa Bolsa-Família. Este trabalho pretende também investigar a existência ou não de um conceito de necessidades no debate contemporâneo sobre renda mínima e a adoção desse conceito nas atuais políticas sociais brasileiras de distribuição de renda.

\section{Palavras-chave}

Políticas sociais; renda mínima; BolsaFamília.

\begin{abstract}
This article presents a political assessment of the concept and formation of a social policy that has, as its primary strategy, monetary transfer programs. Therefore, this research explains the outline of a minimum income policy, in Brazil, based on the unification process of the guaranteed wage programs around the government program called "Bolsa-Família" (Family Allowance). This article also investigates the existence or inexistence of a necessity concept in today's debates about minimum income and the use of such a concept as a guideline for social policies for income distribution, in Brazil, today.
\end{abstract}

\section{Keywords}

Social policies; minimum income; family allowance. 


\section{INTRODUÇÃO}

Este trabalho pretende investigar o conceito de necessidades ${ }^{1}$ que orienta a discussão sobre os programas de garantia de renda mínima, em âmbito nacional, e verificar se os formuladores dos programas de complementação de renda adotam ou não um conceito de necessidades na formulação da política.

A partir dessa investigação, discutem-se os delineamentos de uma política de renda mínima no Brasil e analisam-se os fundamentos teóricos subjacentes ao processo de unificação dos programas de garantia de renda mínima existentes na sociedade brasileira em torno do programa de complementação de renda Bolsa-Família. A discussão sobre a política de renda mínima, no Brasil, na década de 90, está relacionada com o quadro de contradição social registrado na nova dinâmica política e econômica da sociedade brasileira, marcada pelo processo de reestruturação produtiva neoliberal e pela reedição das políticas sociais de caráter compensatório e assistencialista, como é o caso da grande maioria dos programas de garantia de renda mínima, destinados a combater a pobreza.

\section{NOTAS SOBRE A EXPERIÊNCIA BRASILEIRA DE PROTEÇÃO SOCIAL E A PREDOMINÂNCIA DOS PROGRAMAS DE GARANTIA DE RENDA}

No Brasil, diferentemente dos países centrais do capitalismo, os impactos da reestruturação produtiva neoliberal fazem-se sentir somente na transição dos anos 80 para os anos 90 e atingem particularmente o sistema de proteção social brasileiro. Dessa forma, compreende-se por que a propagação das idéias concernentes ao debate internacional sobre programas de garantia de renda mínima só vai ocorrer, na realidade brasileira, no início da década de 90, com o desmonte das legislações social e trabalhista e o processo de dessindicalização dos trabalhadores brasileiros.

Faz-se necessário, contudo, contextualizar, minimamente, a experiência de proteção social brasileira, tendo como referência histórica o período de transição democrática, que assinala uma ruptura com a concepção de política social vigente entre 1964 e 1984 e antecede o surgimento do primeiro projeto de um programa de garantia de renda mínima a ser efetivado em todo o território brasileiro.

\footnotetext{
${ }^{1}$ Nesta pesquisa, analisa-se o conceito de necessidades sociais com base na obra marxiana. Importa registrar duas acepções utilizadas por Marx, nos Manuscritos Econômicos e Filosóficos de 1844, para o termo "necessidades": 1) necessidades biológicas, naturais, orgânicas; 2) necessidades humanas, sociais, históricas e, portanto, exteriores, postas pela sociedade. Nessa perspectiva de análise, as necessidades básicas não se confundem com o mínimo social de existência, e as necessidades sociais extrapolam a construção das necessidades básicas identificadas na imediaticidade da sociedade burguesa.
} 
Importa destacar que, a partir de meados da década de 60 e durante a instauração dos governos militares, observa-se uma clara modificação no conteúdo do Estado brasileiro, que deixa de ser eminentemente paternalista e populista para tornar-se mais tecnocrático e centralizador. Pode-se afirmar que, nesse período da história brasileira, as políticas sociais assumem um novo formato e ocupam um outro lugar no planejamento central do governo (ao deixar de ser mero apêndice da política econômica do governo).

Como constata Mota (1995), no pós-64, com a finalidade de atender as exigências do modelo econômico adotado nos governos militares, procede-se a uma "expansão seletiva da seguridade social", principalmente nos sistemas de previdência e saúde, em função do crescimento da massa de trabalhadores assalariados no setor urbanoindustrial. Na prática, essa ampliação da seguridade concretiza-se por meio da expansão dos programas sociais - caracterizados e diferenciados em função da clientela atendida -, da privatização da assistência médicosocial, da criação da previdência complementar privada e do desmantelamento dos mecanismos de controle e participação dos trabalhadores no sistema de proteção social vigente até 1964 .

Trata-se de um "movimento sincrônico de assistencialização/ privatização da seguridade social" (MOTA, 1995, p. 147). Mota (1995, p. 141) assim explica o que ocorreu na década de 70:

[consolida-se] a dupla face das políticas sociais tecida nos finais dos anos 60: de um lado, as políticas voltadas para a reprodução da força de trabalho contratada pelo capital monopolista; de outro, as políticas residuais voltadas para a reprodução do trabalhador do setor não monopolista, como bem demonstra toda a legislação criadora dos sistemas privados de proteção social.

Com o esgotamento do milagre econômico, no final dos anos 70, inicia-se na sociedade brasileira um processo de abertura militar, e novas mudanças são registradas no âmbito das políticas de proteção social: quer seja sob a pressão exercida pelas massas por meio da atuação dos movimentos sociais organizados, quer seja pelo movimento antecipatório por parte do Estado brasileiro. Como diz Pereira (2000, p. 144), no contexto de abertura militar, "a política social passou a ser estrategicamente intensificada, não como resposta conscienciosa às necessidades sociais, mas como uma via de reaproximação do Estado com a sociedade".

A partir de 1985, há uma ruptura com a concepção de política social vigente entre 1964 e 1984, pautada pelo compromisso mais eqüitativo de proteção social. O período de transição democrática é marcado, profundamente, por dois fatos históricos importantes do cenário social 
brasileiro: primeiro, a convocação da Assembléia Nacional Constituinte, em 1986, e, segundo, o reconhecimento social de uma concepção de proteção social mais universalista e democrática, assentada num sistema de Seguridade Social mais amplo em defesa do direito de cidadania.

Com a promulgação da Constituição de 1988 e a instauração de um novo pacto social, o Estado brasileiro passa a ter maior responsabilidade na regulação, no financiamento e na provisão de políticas sociais, com a universalização do acesso da população aos benefícios e serviços públicos e a ampliação do caráter distributivo da seguridade.

Importa destacar o caráter progressista da Constituição de 1988, que traz avanços e reformulações em toda a área social. Por exemplo, na área do trabalho, registra-se a redução da jornada de trabalho para 44 horas semanais, as férias anuais remuneradas mais 1/3 de salário, a estabilidade de emprego dos funcionários públicos, a licença paternidade, o direito de greve, etc.; na área da educação, reafirma-se o princípio da universalização do ensino fundamental e a manutenção da gratuidade do ensino público em todos os níveis, assim como a afirmação da creche como um serviço de importância na preparação de crianças de até 6 anos; finalmente, na área da seguridade social, incorporam-se a saúde, a assistência (caráter distributivo) e a previdência social (caráter contributivo) a um conjunto integrado de proteção social pública na perspectiva da cidadania.

No que concerne à área da Seguridade Social, constata-se um número maior de mudanças. Os benefícios e as formas de organização são pautados pelo princípio da universalidade nas três políticas sociais que fazem parte do tripé da seguridade: a saúde, a previdência e a assistência. Com relação à saúde, implanta-se um Sistema Único de Saúde (SUS), com a finalidade de operar sob a forma de uma rede integrada, descentralizada e regionalizada. Tal proposta defende um tratamento igualitário e universal para toda a população. No que diz respeito à previdência, incorporam-se, da forma mais democrática, todos os cidadãos trabalhadores (urbanos, rurais e domésticos). E, no que tange à assistência social propriamente dita - a que mais se alterou em relação às constituições passadas -, rompe-se com as práticas assistencialistas do passado e adota-se uma postura mais democrática de política social dirigida para determinados segmentos sociais, como família, gestantes, crianças, adolescentes, idosos, pessoas portadoras de deficiência e desempregados afetados em suas necessidades físicas.

Não resta dúvida de que a Constituição de 1988 ampliou, significativamente, o padrão de seguridade social com a universalização dos serviços públicos e uma maior participação dos usuários na gestão do sistema. Nesse contexto, é visível, também, a ampliação das 
reivindicações dos trabalhadores brasileiros, seja por meio de contratos coletivos de trabalho, seja por meio de propostas encaminhadas pelas centrais sindicais e pelos partidos políticos mais progressistas, institucionalizando-se novos direitos políticos e sociais.

Diz Netto (2003, p. 77):

o essencial da Constituição de 1988 apontava para a construção - pela primeira vez assim posta na história brasileira - de uma espécie de Estado de Bem-Estar Social: não é por acaso que, no texto constitucional, de forma inédita em nossa lei máxima, consagram-se explicitamente, como tais e para além de direitos civis e políticos, os direitos sociais (coroamento, como se sabe, da cidadania moderna). Com isto, colocava-se o arcabouço jurídico-político para implantar, na sociedade brasileira, uma política social compatível com as exigências de justiça social, equidade e universalidade.

Contudo, as conquistas sociais estabelecidas na Constituição de 1988 não se concretizaram plenamente na prática. Vários preceitos constitucionais foram aviltados durante os dois mandatos presidenciais de Fernando Henrique Cardoso (FHC) que, por meio de um conjunto de medidas provisórias, fez valer o projeto neoliberal que compreende, entre outras coisas, a desestatização, a desregulamentação econômica e social, a privatização do patrimônio e dos serviços públicos e a flexibilização do trabalho e da produção.

Segundo Draibe (1999, p. 13), com a introdução do projeto macroeconômico de base neoliberal no cenário brasileiro, é possível identificar pelo menos três linhas de impacto na operacionalização das políticas sociais: "a fragilização dos programas universais de saúde e educação, a tendência à assistencialização da política e a quebra da solidariedade nos regimes previdenciários reformados". No plano dos valores, observa-se uma combinação de concepções universalistas e concepções focalizadas, e no plano institucional identificam-se três orientações principais: 1) a descentralização da prestação de serviços sociais; 2) o aumento relativo da participação social nos programas sociais; 3) a ampliação das parcerias entre o setor público e privado, o setor privado lucrativo e, principalmente, o setor privado sem fins de lucro sob a nova forma de organização não-governamental (DRAIBE, 1999, p. 13).

Netto (2003, p. 88) afirma que, nos governos FHC, "a política social aparece inteiramente subordinada à orientação macroeconômica que, por sua vez, é estabelecida pelos ditames do grande capital". Continua o autor:

o projeto de FHC reduz o protagonismo do Estado a uma espécie de pronto-socorro social, donde um enfrentamento à questão social caracterizado pelo focalismo das ações e seu caráter intermitente, derivado da natureza de uma 
intervenção basicamente emergencial - o modelo dessa política é paradigmaticamente oferecido pelo Comunidade Solidária (NETTO, 2003, p. 88).

Para Lesbaupin (2002, p. 9), um "verdadeiro desmonte da nação [...] foi realizado pelo governo FHC em seu duplo mandato". Com o argumento orquestrado pela mídia de que as empresas estatais são "ineficientes", "obsoletas" e "dispendiosas", inicia-se um processo de privatização sem limites na história brasileira. E, com a desculpa da redução de custos e do pagamento da dívida externa, várias empresas estatais são privatizadas sem o retorno que o governo apregoava.

No campo social, o desastre foi ainda maior com a redução de investimentos e a extinção de vários programas sociais (por exemplo, os programas "Saneamento é vida", "Saúde do trabalhador" e "Controle de Hanseníase e Outras Dermatoses"). Mesmo "o Bolsa-Escola, objeto de intensa propaganda do governo, que contava com uma previsão de recursos da ordem de $\mathrm{R} \$$ 1,7 bilhão, gastou $\mathrm{R} \$$ 501,3 milhões, ou seja, 29,1\%" (LESBAUPIN, 2002, p. 41). No que diz respeito à saúde, o resultado da implantação das políticas neoliberais foi ainda mais aterrador, pois, "na perspectiva do Banco Mundial, a saúde não é vista como um direito, ao qual todos devem ter acesso gratuitamente" (LESBAUPIN, 2002, p. 43). Quanto à educação, "o projeto do governo FHC em relação à universidade pública foi executado seguindo as recomendações do Banco Mundial para o setor" (LESBAUPIN, 2002, p. 46).

No que se refere às desigualdades sociais, afirma ainda Lesbaupin (2002, p. 55):

o Brasil disputa hoje o primeiro lugar em desigualdade social no mundo: o coeficiente de Gini é de 0,60 - exatamente o de vinte anos atrás. [...] Considerando-se o coeficiente de Gini, num conjunto de 92 países para os quais se têm dados, o Brasil ocupa a 3.a pior posição, depois apenas da África do Sul e de Malavi. Quando se calcula a renda média dos 20\% mais ricos e a dos 20\% mais pobres, o Brasil é o país que apresenta o mais alto nível de desigualdade social. E, quando se considera a razão entre a renda média dos 10\% mais ricos e a dos $40 \%$ mais pobres, num conjunto de 50 países para os quais se dispõe de dados, o Brasil ocupa a pior posição em desigualdades de renda.

\footnotetext{
${ }^{2}$ Francisco de Oliveira, no prefácio do livro Brasil em contra-reforma: desestruturação do Estado e perda de direitos, de Elaine Behring, sintetiza de forma brilhante o que representa essa contra-reforma do Estado brasileiro para os trabalhadores. Repetindo Oliveira: "a contrareforma do Estado, que é uma contra-revolução, é o movimento pelo qual o capital tenta anular os novos atores políticos e tampar outra vez a Caixa de Pandora da desarrumação da relação de dominação. Nem se trata, pois, de retirar a tutela do Estado sobre os cidadãos, nem estamos frente a um movimento de supressão do Estado pelo desaparecimento do conflito de classes. A esse canto de sereia neoliberal há que tapar os ouvidos, como Ulysses, e a melhor forma de fazê-lo é o desmascaramento na teoria e na prática dos argumentos e "reformas" (OLIVEIRA, 2003, p. 17).
} 
Continua Lesbaupin (2002, p. 56): "em 1999, o Brasil tinha cerca de $34 \%$ da população vivendo em famílias com renda inferior à linha de pobreza e 14\% em famílias com renda inferior à linha da indigência: cerca de 532 milhões de brasileiros podem ser classificados como pobres e 22 milhões como indigentes".

Com relação à contra-reforma ${ }^{2}$ implementada pelo Estado brasileiro, iniciada ainda na era Collor e desenvolvida plenamente nos dois mandatos do presidente Fernando Henrique, Behring (2003, p. 199) afirma que o corte nos recursos da área social representa "o aspecto mais perverso" dessa contra-reforma:

a reforma do Estado, tal qual está sendo conduzida, é a versão de uma estratégia de inserção passiva (Fiore, 2000, p. 37) e a qualquer custo na dinâmica internacional e representa uma escolha político-econômica, não um caminho natural diante dos imperativos econômicos. Uma escolha, bem ao estilo da condução das classes dominantes brasileiras ao longo da história, mas com diferenças significativas: esta opção implicou, por exemplo, uma forte destruição dos avanços, mesmo que limitados, sobretudo se vistos pela ótica do trabalho, dos processos de modernização conservadora que marcaram a história do Brasil (BEHRING, 2003, p. 199).

No atual governo do presidente Luiz Inácio Lula da Silva, parece que essa "escolha político-econômica", feita nos governos anteriores, segundo Behring, está sendo mantida e levada a cabo sem grandes questionamentos. Por meio de um discurso aparentemente de esquerda, o atual governo federal, novamente, aposta na subordinação das políticas sociais às orientações econômicas do capitalismo internacional.

Desse modo, trata-se, tão-somente, de implantar, como disse Behring (2003, p. 199), o "pensamento único difundido em nível internacional" concernente à proteção social, que defende os direitos do capital em detrimento das reais necessidades dos trabalhadores. Esta pesquisa indica a existência, no governo de Lula, de uma tendência (com algumas modificações) para reorientar as políticas sociais com base na reedição de programas de transferência de renda dirigidos à população pobre, com inúmeras condicionalidades, como é o caso dos programas de garantia de renda mínima brasileiros.

\section{DELINEAMENTO DE UMA POLÍTICA DE RENDA MÍNIMA NO BRASIL}

Com base no que foi dito anteriormente, discutem-se o delineamento de uma política de renda mínima no Brasil e analisam-se os fundamentos teóricos subjacentes ao processo de unificação dos programas de garantia de renda mínima existentes na sociedade brasileira em torno do programa Bolsa-Família. 
Cabe ressaltar que o fato de a renda mínima na realidade nacional ter começado a ser debatida somente na década de 90 está diretamente relacionado com a nova configuração política e econômica da sociedade brasileira, caracterizada pelas novas tendências no mercado de trabalho, pela exacerbação da exclusão e da desigualdade social, pelo aumento da violência, pela generalização do desemprego e pela insuficiência de renda da maior parte da população.

Assim sendo, não é por acaso que a discussão de uma política de renda mínima no Brasil somente ganha visibilidade na realidade brasileira no início da década de 90. O marco dessa discussão foi o projeto de lei, de autoria do senador Eduardo Suplicy, aprovado no Senado em 1991, que criava o Programa de Garantia de Renda Mínima (PGRM) para que fosse adotada uma renda mínima em todo o país, à qual teria direito todo indivíduo adulto com mais de 25 anos que não conseguisse rendimento suficiente para suprir as suas necessidades básicas.

De acordo com o projeto de lei do senador Suplicy, o Programa de Garantia de Renda Mínima apresenta as seguintes características: 1) o beneficiário tem o direito de gastar o valor do beneficio recebido pelo programa como lhe convier; 2) o valor monetário pago pelo programa, apurado mensalmente, seria destinado a complementar o salário, e, desse modo, os indivíduos não dependeriam da situação de emprego para ter acesso ao beneficio; 3) a proposta de renda mínima, como está formulada na lei, evitaria fluxos migratórios.

Após a discussão e a aprovação do PGRM do senador Suplicy, na sessão de 16 de dezembro de 1991, o projeto preliminar recebeu um substitutivo de lei do Senado, que previa uma implantação gradual na seguinte escala: primeiro o programa atingiria os indivíduos com 60 anos ou mais até o ano de 1994; depois todos os maiores de 55 anos ou mais até o ano de 1995; finalmente, os indivíduos maiores de 25 anos.

Apesar da enorme aceitação por parte dos parlamentares no Senado Federal do Brasil, o projeto de renda mínima do senador Suplicy recebeu inúmeras críticas, dentre as quais se destacam: 1) a insuficiência de recursos fiscais, por parte do Estado, para financiar o programa; 2) a complexidade administrativa do Governo Federal, Estados e municípios, que dificultaria a gestão do programa; 3) as dificuldades de fiscalização das declarações de rendimentos dos indivíduos (considerando que 50\% da força de trabalho encontram-se na informalidade); 4) a incapacidade do Estado brasileiro para mudar a estrutura econômica que gera a marginalidade econômica e a exclusão social; 5) o problema endêmico da corrupção no Brasil; 6) a possibilidade de a implantação do PGRM desestimular o trabalho.

Vale a pena ressaltar que o Projeto de Lei PGRM do senador Suplicy, aprovado no Senado, distingue-se, em alguns pontos, dos primeiros programas de garantia de renda mínima implementados em âmbito local, 
como, por exemplo, o Programa de Garantia de Renda Bolsa Familiar para Educação (Bolsa-Escola), no Distrito Federal, destinado a toda família que não ganhasse pelo menos meio salário mínimo mensal per capita e tivesse crianças de 7 a 14 anos, e o Programa de Garantia de Renda Mínima Familiar, em Campinas, também dirigido a toda família com renda inferior a meio salário mínimo mensal e com crianças de até 14 anos. Tais programas de transferência de renda, na maioria dos casos, objetivam retirar as crianças das ruas e combater o trabalho infantil, são direcionados às famílias com crianças e adolescentes menores de 14 anos ou de 16 anos, e condicionam a complementação monetária também à freqüência na escola e nos postos de saúde, bem como à participação dos adultos em cursos de capacitação e treinamento profissional.

A partir da implantação e da aceitação política desses dois programas, proliferam no interior do País diversos projetos de programas de complementação de renda. Até 1998, eram mais de 75 em andamento em diversos municípios brasileiros.

\section{PGRM: UM MECANISMO DE COMPLEMENTAÇÃO DE RENDA}

Carlos Alberto Ramos (1994), num trabalho do início da década de 90, intitulado Programa de Garantia de Renda Mínima, afirma que não resta dúvida de que o surgimento dos programas de garantia de renda explica-se por duas razões: 1) a contradição social entre o antigo sistema de proteção social, que privilegiava as políticas tradicionais, e uma nova dinâmica econômica e social, que representa novas tendências no mercado de trabalho; 2) a crescente exclusão social e a impossibilidade de integração de uma grande parte da população ao mercado de trabalho. Daí a necessidade de uma compensação monetária como uma política que complementa as históricas conquistas do mundo do trabalho e estende-se ao direito de cidadania.

É notório que uma política de renda mínima com base no Imposto de Renda Negativo (IRN) "não introduz restrições institucionais ao livre jogo da oferta e da demanda e, ao outorgar uma compensação monetária, possibilita aos beneficiados um perfil de consumo compatível com suas preferências individuais" (RAMOS, 1994, p. 12). Entretanto, a garantia de renda mínima não deve significar a substituição integral das políticas tradicionais, como defende o IRN, mas a complementação de um antigo Estado de bem-estar. Esclarece Ramos (1994, p. 15):

No caso do Brasil, a renda mínima é assumida como um dos instrumentos suscetíveis de melhorar a distribuição de renda. A histórica dificuldade de elevar os salários reais via política salarial induz a pensar que mudanças na distribuição de renda devem passar ou ser complementadas, por medidas que estejam à margem do mercado de trabalho. 
Na opinião de Ramos, uma política de renda mínima deveria estar atrelada a programas que envolvam reformas estruturais, para eliminar as raízes das desigualdades sociais, e não apenas atuar na minimização da exclusão social por meio do combate à fome e à pobreza a curto prazo. Dessa forma, a implementação de um programa de complementação de renda implica uma discussão mais ampla sobre a relação do PGRM com outras políticas sociais (como, por exemplo, as políticas de geração de emprego).

Em recente trabalho, Márcio Pochmann (2002, p. 86) admite que a grande "novidade" dos programas de garantia de renda e combate à pobreza reside no fato de que eles "rompem com a lógica assistencialista, presente na tradição das políticas sociais no Brasil e que tem suas origens nas bases sobre as quais se ergueu o sistema de proteção social: emprego-renda - contribuição - benefícios sociais". Apesar das diferentes denominações recebidas pelos programas de garantia de renda mínima em cada localidade onde foram instituídos, os programas "explicitaram algo em comum: a articulação, de forma inédita e inovadora, do reforço à renda familiar e do estímulo à educação das crianças como opção estratégica de combate à pobreza" (POCHMANN, 2002, p. 86).

Ainda, segundo Pochmann (2002, p. 86), "no Brasil, algumas avaliações de programas de renda mínima revelam que as famílias destinam seus recursos para a compra de alimentação, de material para reforma ou melhoria da habitação e de equipamentos que aliviam os afazeres domésticos".

De um modo geral, como observa Silva (1997), os programas de renda mínima na realidade brasileira apresentam as seguintes características: 1) a família aparece como beneficiária dos programas; 2) o público-alvo para o recebimento da renda mínima são famílias pobres com dependentes de até 14 anos de idade; 3) a transferência da renda está associada à possibilidade de redução de problemas sociais negativos ligados a crianças e adolescentes; 4) os critérios de elegibilidade associam renda per capita dos membros da família à idade dos filhos e ao tempo de moradia no município; 5) os programas exigem uma contrapartida para a permanência das famílias nos programas, que tem a ver com o comportamento dos filhos ou dependentes; 6) o benefício, na maioria das vezes, está sendo financiado com recursos públicos previstos nos orçamentos dos Estados e dos municípios e, em determinados casos, provém de doações de organizações não-governamentais. Silva (1997, p. 148) sintetiza:

o objetivo central explícito dos programas de renda mínima, no Brasil, é a melhoria das condições de vida de famílias pobres através de uma transferência monetária associada à exigência de os pais ou responsáveis garantirem a freqüência 
às aulas de crianças e adolescentes (substituindo trabalho infanto-juvenil pela escola), atendimento regular à saúde e sua retirada das ruas. Esse aspecto, a princípio, situa a renda mínima como uma política social de combate à pobreza numa perspectiva de curto e médio prazo.

Lavinas e Varsano (1997, p. 51), no texto intitulado Programa de garantia de renda e ação coordenada de combate à pobreza, também compartilham da idéia de que uma "renda mínima complementar vem fortalecer os mecanismos de solidariedade e de assistência do atual sistema de proteção social", porém esse mecanismo de transferência de renda, por si só, é insuficiente para o combate a pobreza.

Com relação ao debate sobre o papel da renda mínima garantida no conjunto das políticas sociais, os autores ressaltam, pelo menos, três posições diferentes a seguir: 1) a primeira posição defende a incondicionalidade de uma renda de subsistência também denominada benefício universal ou renda de cidadania; 2) a segunda posição rejeita a visão de incondicionalidade de uma renda mínima e a supressão das contrapartidas; 3) a terceira posição insiste nas limitações da renda mínima como política de combate à pobreza e defende uma ampliação do antigo sistema de proteção social em outras bases mais solidárias, desvinculadas do exercício de uma atividade formal.

Ainda no que diz respeito às diferentes posições em relação à implementação de uma renda mínima garantida, vale a pena registrar determinadas discordâncias. No que se refere à unidade a ser beneficiada, discute-se se deve ser a família ou o indivíduo o destinatário do programa; no que concerne ao financiamento, observa-se a existência de modelos distintos de co-participação entre as esferas de governo, bem como diferenças quanto à gestão administrativa e à execução dos programas.

Apesar de todas as diferenças existentes entre os vários programas de garantia de renda instituídos internacionalmente, na maioria das vezes, há uma base comum:

existem condicionalidades, são universais e destinam-se a todos os que se encontrem em situação de necessidade decorrente da insuficiência de renda, são um direito subjetivo, isto é atribuído com base numa demanda feita pelo próprio interessado; são um direito condicional, pois implicam o respeito a certas prerrogativas, e, em alguns casos, contrapartidas, como a disponibilidade para exercer um trabalho, e são um direito subsidiário, ou seja, têm um valor modulado pelo montante das demais prestações sociais e pela renda individual ou familiar (LAVINAS; VARSANO, 1998, p. 51).

Lavinas e Varsano (1997) ressaltam, principalmente no que se refere à unidade a ser beneficiada, as dificuldades de desenvolvimento 
pessoal dos membros da família e a questão da seletividade dos programas em relação à população-alvo - somente famílias com crianças. Os autores afirmam que a vinculação da concessão dos benefícios a essas condicionalidades é uma das características dos PGRM nacionais, porque, no Brasil, ainda existe trabalho infantil para ampliar a capacidade de geração de renda da família. De acordo com eles, essa característica é a principal diferença entre os programas de renda mínima nacionais e os programas de renda mínima europeus, que apostam no resgate dos vínculos dos beneficiários com a atividade econômica, por meio da inserção produtiva no mercado de trabalho. Defendem Lavinas e Varsano (1997, p. 67):

o que nos parece mais adequado é exigir como única contrapartida obrigatória, no caso da criança, sua freqüência na escola [...] e, no caso dos adultos, a participação em iniciativas voltadas para a sua participação e inserção profissional. [...] visitas periódicas a postos de saúde e participação em ações em interesse da comunidade devem ser estimulados como direitos de cidadania, mas não podem transformar-se em imposição sujeita ou não a sanções.

Para Lavinas e Varsano, os PGRM devem ser de cobertura universal, de continuidade ilimitada (enquanto a renda do beneficiário estiver abaixo do estabelecido pelo programa), sem restrições orçamentárias, e o governo federal deveria participar do programa como entidade normativa ou como co-financiador do programa.

Nesse caso, os PGRM não podem ser considerados como um substituto de outras políticas sociais compensatórias, pois, apesar de ocuparem um lugar central em uma ação coordenada para a erradicação da pobreza, por si só são insuficientes para combater as desigualdades sociais e a exclusão social presentes no País. Embora, no Brasil, o combate à pobreza seja urgente, "o açodamento na realização de um programa dessa envergadura (PGRM) teria como resultado quase certo um grande desperdício de recursos" (LAVINAS; VARSANO, 1997, p. 70).

Faz-se necessário complementar o PGRM com outras ações do governo para combater as desigualdades sociais. Lavinas e Varsano (1997) propõem o que denominam Programa de Ação Coordenada (PAC) para combater a pobreza. Trata-se de um "novo tipo de ação social, mais coordenada e adequada às verdadeiras necessidades da população carente [...] e que pretende reduzir a pobreza por meio de uma intervenção social qualitativamente nova (que prioriza o atendimento dos mais carentes, procura fortalecer a cidadania e evita a exclusão social)" (LAVINAS; VARSANO, 1997, p. 77).

Para a concretização dessa proposta, chamada PAC, os autores sugerem uma série de ações governamentais (nas esferas federal, estadual e municipal) que compreendem ações de âmbito mais geral como investimentos em atividades públicas consideradas essenciais 
(saneamento, moradia, educação alimentar e transportes) -, ações de nível médio - como a ampliação da rede elétrica, a implantação de sistema de segurança e serviços básicos prestados à população, como educação e saúde, a expansão de infra-estrutura viária e de comunicação, a criação de empregos - e ações de alcance individual - como a regularização de instrumentos de posse ou propriedade, a regularização de serviços de orientação jurídica, a implementação de campanhas educativas, o financiamento de lotes e construção de casas, a criação de programas de alfabetização, treinamento e capacitação profissional.

De acordo com essas orientações, as atribuições do PAC estariam relacionadas diretamente com o atendimento das necessidades básicas da população mais pobre - por exemplo, educação, saúde, infra-estrutura, urbanização, segurança pública, assistência social, saneamento básico, transporte, lazer ou esporte, habitação e regularização fundiária, emprego e geração de renda, promoção e extensão rural, e desenvolvimento integrado.

É evidente que a proposta de Lavinas ${ }^{3}$ e Varsano (1997) diferenciase fundamentalmente da proposta inicial de PGRM, com base no IRN, defendida pelo senador Suplicy, como também dos demais programas de complementação de renda que foram instituídos na realidade brasileira em âmbito local. Trata-se, também, de uma proposta que difere daquela adotada pelo atual governo do presidente Luiz Inácio Lula da Silva, que apostou na unificação dos programas de distribuição de renda existentes nos governos anteriores e na criação do programa de complementação de renda, de abrangência nacional, denominado Programa de Complementação de Renda com Condicionalidades Bolsa- Família.

\section{PROCESSO DE DISCUSSÃO DA UNIFICAÇÃO DOS PROGRAMAS}

Ao longo dos anos 90, observa-se uma série de mudanças nas estratégias políticas para consolidar uma política de renda mínima e romper com uma lógica assistencialista de combate à pobreza ${ }^{4}$ que

\footnotetext{
${ }^{3}$ Em entrevista publicada no jornal Folha de S.Paulo, em 28 de novembro de 2004, Lavinas propõe a universalização do programa instituído pelo atual governo do presidente Lula, o Bolsa-Família. Argumenta que os programas de transferência de renda seriam mais eficientes e teriam maior impacto na redução da pobreza se o acesso ao benefício fosse irrestrito para todas as crianças até 16 anos. Ademais, Lavinas questiona a eficácia do impacto do programa e critica o governo federal pela redução de políticas universais em benefício de políticas complementares de renda. Conclui Lavinas: "dar para todos não é um desperdício, mas dar apenas para os pobres gera um estigma. Quando o benefício é para todos, gera um mecanismo de coesão social".

${ }^{4}$ No que concerne ao combate à pobreza, desde os anos 90, o Brasil adota as orientações dos últimos Relatórios do Banco Mundial para a América Latina, baseadas em uma visão neoliberal que vê o mercado como o principal organizador da sociedade e a sociedade como um conjunto de indivíduos atomizados.
} 
culminaram com o processo de unificação dos programas brasileiros de distribuição de renda.

A discussão sobre a unificação dos programas de complementação de renda existentes no País inicia-se durante o período de transição do governo Fernando Henrique Cardoso para o governo Luiz Inácio Lula da Silva. Depois da posse, e após um intenso processo de negociações entre membros do governo de transição do governo Lula, com a participação de intelectuais da área de políticas sociais que haviam sido convidados para adicionar massa crítica às discussões, adota-se uma política nacional de distribuição de renda voltada para a redução da pobreza e para o combate à fome. A finalidade dessa política nacional é a realização de uma transferência monetária para permitir às famílias beneficiadas pelo programa a escolha na aquisição de bens e serviços para satisfazer suas necessidades básicas.

Como resultado das inúmeras discussões sobre políticas sociais, com a participação ativa do presidente Lula e de participantes do governo de transição, é elaborado um relatório ${ }^{5}$ que apresenta um diagnóstico dos programas sociais de distribuição de renda implementados pelos governos anteriores, vinculados a distintos ministérios. Nesse relatório, apresentam-se os programas de distribuição de renda existentes, seus principais problemas, suas relações com o Cadastramento Único (CADUNIO), sugestões e encaminhamentos para a superação dos problemas no sentido de uma adequação do programa aos compromissos do atual governo Luiz Inácio Lula da Silva.

Esse relatório aponta um conjunto de problemas diretamente relacionados com os programas de complementação de renda instituídos pelos vários ministérios - Programa de Renda Mínima, vinculado à Educação Bolsa-Escola, Programa de Renda Mínima, vinculado à Saúde Bolsa Alimentação, Programa de Erradicação do Trabalho Infantil, Programa Agente Jovem, Bolsa Renda e Auxilio Gás. Os problemas evidenciados nesse relatório estão associados a determinadas características dos programas citados, entre os quais se destacam:

a superposição do público-alvo; um custo administrativo no que concerne aos ministérios e secretarias envolvidos e ao agente bancário (CEF); a pulverização de recursos públicos; a desvinculação de outras políticas que possam funcionar como porta de saída e, muitas vezes, tratamento diferenciado para o mesmo público-alvo (Relatório da Assessoria da Presidência da República do Governo de Transição do Presidente Lula da Silva, p. 14).

\footnotetext{
${ }^{5}$ Esse relatório faz parte de um conjunto de documentos sobre o processo de discussão e gestação do programa Bolsa-Família e encontra-se sob a guarda da Assessora Especial da Presidência da República do Governo Lula da Silva, Sra. Miriam Belquior, que na ocasião coordenou as discussões do processo de unificação dos programas de distribuição de renda existentes.
} 
O relatório contém uma série de encaminhamentos e recomendações que deveriam ser previamente trabalhados tendo em vista a integração dos programas de complementação de renda instituídos. Em um primeiro bloco de recomendações, que trata das questões operacionais, o relatório encerra inúmeras indicações: a) necessidade de atualização, validação e consolidação do Cadastro Único $(\mathrm{CADUNIO})^{6}$ realizado ainda no governo do presidente Fernando Henrique Cardoso, que apresenta determinadas inadequações no preenchimento dos campos; b) necessidade de revisão do papel da Caixa Econômica Federal (CEF) como agente operador e financiador e a possibilidade de utilização de outros agentes pagadores; c) necessidade de padronização da renda familiar per capita para efeitos de ingresso no programa; d) necessidade de atualização do público-alvo potencial dos programas; e) rediscussão da conveniência de manutenção das contrapartidas dos municípios. Em um segundo bloco de recomendações, o relatório aborda questões mais relacionadas à gestão e à inserção institucional, como a unificação dos cadastros e o cartão único e a idéia de desenvolvimento com inclusão, articulando-se o programa de complementação de renda com outros programas e políticas sociais.

As recomendações feitas no relatório refletem os discursos dos principais articuladores que participaram da discussão do processo de unificação dos programas de transferência de renda.

Segundo a documentação analisada e as entrevistas realizadas e publicadas, referentes à formulação e à concepção do programa BolsaFamília, a unificação dos programas visa garantir mais recursos para as famílias beneficiadas e pretende racionalizar os recursos públicos do governo federal e reduzir gastos operacionais. Ademais, a parceria entre o governo federal, os Estados e os municípios da União7, por meio de convênios de cooperação, permitiria uma melhor operacionalização dos programas de garantia de renda.

\footnotetext{
${ }^{6}$ Com base no texto de Carlos Alberto Ramos e Ricardo Santana, Subsídios para a reformulação do questionário do Cadastro Único (também denominado CADUNIO), se compararmos os dados divulgados na Pesquisa Nacional de Amostragem por Domicílios (PNAD), de 1999 e 2001, com os valores obtidos e o público-alvo (indivíduos integrantes de famílias pobres) do CADUNIO, com exceção de determinados campos específicos do questionário, não se encontram grandes diferenças, e os resultados são bastante compatíveis. Os autores aconselham, como manda a prudência, dada a abrangência do cadastramento (20 milhões de pessoas), aguardar dois ou três anos para realizar um outro recadastramento.

${ }^{7}$ Em 30 de setembro de 2003, foi firmado um compromisso pela inclusão social entre o Governo Federal, os governos estaduais e o Distrito Federal, "com o objetivo, dentre outros, de conferir maior racionalidade, organicidade e efetividade às ações de combate à fome e à pobreza, de emancipação das famílias e de promoção do desenvolvimento sustentável das comunidades" (Termo de Cooperação que entre si celebram a União, por intermédio do Ministério do Desenvolvimento Social e Combate à Fome, e o Estado-Membro do Rio de Janeiro).
} 
Pautado pela orientação política do governo, o Bolsa-Família tem como meta a unificação dos procedimentos de gestão e de execução das ações de transferência monetária dos programas de complementação de renda já existentes, como o Programa Nacional de Renda Mínima do Ministério da Educação - o Bolsa Escola (abril de 2001) -, o Programa Nacional de Renda Mínima do Ministério da Saúde - o Bolsa Alimentação (setembro de 2001) -, o Programa Auxílio Gás (janeiro de 2002) do Ministério das Minas e Energia e o Programa Nacional de Acesso à Alimentação (PNAA) - "Cartão Alimentação" (junho de 2003) - do Ministério de Segurança Alimentar.

\section{IMPLANTAÇÃO DO PROGRAMA DE RENDA MÍNIMA BOLSA-FAMÍLIA}

Um dos elementos mais inovadores do Bolsa-Família, como programa de complementação de renda, está relacionado com a unificação das ações da assistência de vários ministérios. Assim, o Ministério da Saúde fiscaliza o acompanhamento das exigências relacionadas à saúde, como o desenvolvimento infantil, o pré-natal, o puerpério e a carteira de vacinação, o Ministério da Educação controla a freqüência escolar e o Ministério do Desenvolvimento Social articula e supervisiona as ações governamentais.

Com o lançamento do Bolsa-Família, em outubro de 2003, o atual governo federal incorpora na sua agenda política o programa de complementação de renda com condicionalidades, que pretende, não substituir ações governamentais na área da saúde e da educação, mas ampliar o acesso a determinados direitos básicos do cidadão relacionados à saúde, à educação e à alimentação.

Na ocasião do lançamento do programa, o presidente Lula proferiu um discurso e declarou que, "com o Bolsa-Família, milhões de famílias brasileiras, até hoje excluídas dos direitos mínimos de cidadania, estão sendo protegidas para que possam olhar para si mesmas e descobrir as suas próprias forças de emancipação" (SILVA, 2003).

Por meio da Lei n. ${ }^{\circ}$ 10836, de 9 de janeiro de 2004, o Programa de Complementação de Renda Bolsa-Família passou a ter validade em todo o território nacional. O Bolsa-Família apresenta as seguintes características: os benefícios pagos são destinados a famílias que vivem em situação de extrema pobreza; o corte do valor do beneficio foi fixado pelo governo a partir de uma média entre os complementos de renda já existentes, como o programa Bolsa-Escola e o programa Bolsa Alimentação, e o benefício será pago preferencialmente à mulher; os recursos destinados à transferência de renda são provenientes de dotações alocadas no Governo Federal e podem ser complementados pelos Estados e pelos municípios. 
De acordo com a Lei n. ${ }^{\circ}$ 10836, o Bolsa-Família prevê contrapartidas da família beneficiada, como, por exemplo, ida a posto de saúde para a realização de exame pré-natal, acompanhamento nutricional, vacinação de crianças e freqüência escolar. A permanência das famílias beneficiadas no programa Bolsa-Família está diretamente relacionada com a manutenção dos critérios de elegibilidade e com o cumprimento das condicionalidades ou contrapartidas sociais. A estimativa do governo quanto ao número de beneficiados atendidos pelo programa é ascendente e cresce consideravelmente a cada ano ${ }^{8}$.

Conforme o material promocional e de divulgação do programa, "o Bolsa-Família fortalece a agenda do Fome Zero e contribui com o seu objetivo de assegurar três refeições por dia para todos os brasileiros na medida em que amplia o acesso à alimentação e cria portas de saída da situação de exclusão social" (Brasil, um País de Todos, Governo Federal, Programa Bolsa-Família).

Com relação à operacionalização, em um primeiro momento, caberiam ao Conselho Gestor Interministerial do Bolsa-Família a formulação e a integralização das ações políticas do programa, bem como a definição das diretrizes, normas e procedimentos para a implementação do programa. Esse conselho contaria com uma Secretaria Executiva, inicialmente ligada diretamente à Presidência da República e, depois do Decreto n. ${ }^{\circ}$ 5209, de 17 de setembro de 2004, subordinada ao Ministério do Desenvolvimento Social (MDS). Essa Secretaria Executiva seria responsável pela coordenação, pela supervisão, pela avaliação, pela operacionalização e pelo controle do programa e pelas ações relativas à concessão e ao pagamento de benefícios, à gestão do Cadastro Único (CADUNIO), à supervisão do cumprimento das condicionalidades, à articulação com outros ministérios, ao acompanhamento e à fiscalização da execução do programa.

Por meio de um cartão magnético, a Caixa Econômica Federal, agente operador do programa, repassaria os valores dos benefícios para as famílias selecionadas pelo programa. Para a realização da transferência monetária, a identificação da abrangência e a distribuição dos beneficiários, a Caixa Econômica Federal conta com os dados relativos ao censo da população estruturalmente pobre, inclusos no Cadastro Único (CADUNIO).

Em síntese, o Bolsa-Família possui dois grandes objetivos: a) "combater a fome, a pobreza e as desigualdades por meio de transferência de um beneficio financeiro associado à garantia de acesso aos direitos sociais básicos - de saúde, educação, assistência social e

\footnotetext{
${ }^{8}$ No discurso de lançamento do programa Bolsa-Família, o presidente Lula assumiu o compromisso político de atingir 3 milhões e 600 mil famílias beneficiadas pelo programa até dezembro de 2004, e esse número deverá chegar à marca de 11,4 milhões de famílias em 2006.
} 
segurança alimentar"; b) "promover a inclusão social, contribuindo para a emancipação das famílias beneficiárias, construindo meios e condições para que elas possam sair da situação de vulnerabilidade em que se encontram" (BRASIL. MDS. Bolsa-Família: perguntas e respostas).

Em setembro de 2004, na X Conferência Internacional da Rede Européia de Renda Básica, sobre "As perspectivas da renda básica nos países em desenvolvimento", realizada na cidade de Barcelona, o senador Suplicy relatou que, em janeiro de 2004, fora aprovada pelo Congresso Nacional do Brasil e sancionada pelo presidente Lula a Lei n. ${ }^{0}$ 10.835, que institui a renda básica de cidadania incondicional. Essa lei deveria ser implantada gradualmente a partir de 2005, sob a orientação do Poder Executivo, dando prioridade aos mais necessitados, até atingir todos os brasileiros residentes no país e os residentes há mais de cinco anos.

O senador Suplicy apresentou determinados dados relativos ao programa Bolsa-Família, que seria o "precursor da renda básica de cidadania brasileira":

em outubro de 2003, havia 2,7 milhões de famílias beneficiadas pelo programa Bolsa-Família, que foi iniciado principalmente nas regiões mais pobres do Brasil, semi-árido do Nordeste - Norte. Em setembro de 2004, temos mais de cinco milhões de famílias cadastradas. O plano prevê uma expansão para 6,2 milhões de famílias até o próximo mês de dezembro, e para 11,2 milhões de famílias ou cerca de 46,6 milhões de habitantes em 2006 (SUPLICY, 2004, p. 2).

Considerando-se o que foi exposto, a análise documental e as entrevistas realizadas, pode-se afirmar que a eficiência do Bolsa-Família, como qualquer outro programa dessa natureza, é medida mais pela quantidade de pobres assistidos do que pelo provimento das necessidades dos beneficiários do programa, o que deveria ser a finalidade última do programa de complementação de renda.

Ao comparar-se o debate internacional sobre renda mínima e a política de garantia de renda mínima no Brasil, fica evidente a opção do governo e a orientação extremamente pragmática na condução política do processo de unificação dos programas de transferência de renda brasileiros. Observa-se também, em determinados formuladores do programa, sem qualquer demérito pessoal, uma espécie de alienação ideológica, na medida em que mantêm os mecanismos de reprodução do capital $^{9}$.

\footnotetext{
${ }^{9}$ Como observa Francisco de Oliveira, em recente entrevista, o programa Bolsa-Família (alimentação básica para os estratos mais pobres da população) representa a base da "hegemonia às avessas" do governo do presidente Lula e aparece acima da política, acima dos conflitos e acima das classes sociais. Assim sendo, com a implementação do Bolsa-Família, desiste-se de combater as causas estruturais das desigualdades na sociedade brasileira.
} 


\section{CONSIDERAÇÕES FINAIS}

A proposta de política de renda mínima, como foi adotada pelo governo brasileiro por meio da implantação do programa de complementação de renda Bolsa-Família, suscita uma série de interrogações. Em primeiro lugar, a complementação de renda como foi proposta difere consideravelmente de uma alocação universal (como, por exemplo, uma renda social incondicional para assegurar a cada um o direito de participar da riqueza social), visto que essa compensação monetária é condicionada e limitada temporariamente. Em segundo lugar, ainda não é possível afirmar, com base em pesquisas dos institutos oficiais do governo, que esse programa de complementação de renda, na forma como está sendo implementado no território nacional, está favorecendo uma articulação dessa política de renda mínima com o conjunto das políticas sociais. Por último, não resta dúvida de que a complementação de renda pode representar para o trabalhador uma alternativa de garantia de um mínimo de subsistência (o que aumenta consideravelmente o seu poder de negociação no mercado de trabalho), todavia essa complementação não reforça os direitos trabalhistas conquistados historicamente e não invalida nem questiona a relação capital vs trabalho própria da sociedade capitalista de produção.

Embora as escassas pesquisas sobre os impactos dos PGRM nas condições de vida das famílias beneficiadas apontem para o fato de que o benefício pago é quase sempre destinado à alimentação, à moradia, à educação e ao consumo de equipamentos para facilitar as tarefas domésticas, fica claro que a complementação de renda assegurada pelo PGRM satisfaz parcialmente às necessidades básicas da população, pois garante apenas parte do consumo necessário para a sobrevivência dos indivíduos. Não satisfaz, portanto, a um conjunto de bens públicos indispensáveis à manutenção de sua subsistência, tampouco contribui para o desenvolvimento de necessidades sociais que estão além das necessidades de sobrevivência.

Durante o processo de investigação, constatou-se que, no que diz respeito ao debate sobre programas de renda mínima internacionais, na maioria das vezes, a discussão sobre necessidades sociais aparece lateralmente. Quase sempre, a polêmica fica restrita a questões pontuais, como, por exemplo, o provimento dos mínimos sociais de existência, e raramente se estende para a compreensão de um conceito mais amplo de necessidades sociais. Também se identificou uma certa confusão teórica, por parte dos formuladores dos programas, tanto no plano internacional como no âmbito nacional, em relação à compreensão das diferenças conceituais entre mínimos sociais de existência, necessidades básicas e necessidades sociais. 
Como foi demonstrado, a maior parte das propostas de programas de renda mínima de inspiração liberal não questiona a organização do trabalho na sociedade capitalista. Também é evidente que essas propostas de cunho liberal não ultrapassam os limites da sociedade capitalista; suas ações são orientadas por uma lógica de substituição de programas e serviços sociais e incidem, principalmente, no suprimento de determinadas necessidades indispensáveis à sobrevivência daqueles mais desfavorecidos socialmente e incapacitados para o trabalho. Desse modo, a discussão sobre a renda mínima gira em torno das necessidades orgânicas impostas pela condição biológica do ser.

Embora as evidências apontem determinadas mudanças em relação às primeiras propostas liberais, no que tange, principalmente, à proposta de concessão de uma renda mínima, universal, para todo cidadão, independentemente de sua vinculação a qualquer tipo de trabalho, o valor atual da renda concedida ao cidadão, na maioria dos programas registrados, continua sendo muito limitado e, na maioria dos casos, não cobre as suas necessidades básicas. Ademais, ainda prevalece no debate sobre renda mínima a proposta de garantia de uma renda modesta com o intuito de não tirar dos indivíduos a motivação para o trabalho e não ferir a organização do trabalho na atual fase do capitalismo.

Assim sendo, admitir certos avanços nas propostas de base liberal não significa equiparar as duas propostas, a liberal e a distributivista, já que os dois enfoques partem de paradigmas de análise diferentes e excludentes; tampouco pode-se afirmar que a proposta liberal, com todo o "republicanismo" subjacente, representa um mecanismo de complementação monetária favorecedor da construção de uma sociedade alternativa ao capitalismo.

Na prática, os programas de renda mínima de caráter liberal, apesar de reduzirem a pobreza, revelam-se insuficientes para resolver de maneira isolada os problemas estruturais da sociedade capitalista, especialmente em função do desemprego, da recessão econômica, da precarização do trabalho e da desregulamentação dos direitos trabalhistas. Dado um novo conceito de proteção social e o reordenamento dos processos produtivos, contudo, compreende-se que a discussão relativa à renda mínima tenha características ambíguas e conflitantes. No plano internacional, onde o debate está mais avançado, algumas questões continuam a gerar polêmica e não há uma orientação única, principalmente no que se refere à concepção e à institucionalização de programas de garantia de renda.

Mesmo com todas as inovações resultantes do processo de unificação em torno do programa de complementação de renda BolsaFamília, pode-se chegar a algumas conclusões (nem que sejam pontuais, porque a política do governo ainda está em fase de implantação). De 
um lado, o debate político sobre a unificação dos programas em torno do Bolsa-Família carece de uma base teórica e filosófica mais consistente, particularmente quanto à questão da construção e da satisfação das necessidades básicas dos indivíduos na sociedade brasileira, que deveria ser a finalidade última do programa; de outro lado, a proposta de renda mínima, como está constituída na realidade brasileira, não é uma política de Estado de caráter universal, direcionada a todos os cidadãos brasileiros, e só pode ser caracterizada como mais uma política de governo, de caráter pontual, emergencial, para minimizar as desigualdades sociais existentes na sociedade brasileira.

Esse fato parece explicar por que determinadas propostas sobre renda mínima, mesmo com um discurso político de esquerda, baseiamse em premissas teóricas segundo as quais a defesa da garantia de uma renda mínima não deve inviabilizar a gestão do sistema capitalista de produção. Com base nesse raciocínio, pode-se afirmar categoricamente que há uma diferença entre a concepção das propostas de renda mínima de caráter distributivistas, apresentadas em âmbito internacional, e a dos programas de renda mínima em curso na realidade brasileira. Além disso, se a garantia dos direitos sociais e a satisfação das necessidades dos indivíduos desvinculada da venda da força de trabalho alienado estão presentes em determinadas propostas progressistas internacionais, não foi essa, com certeza, a opção teórica adotada na condução, na discussão e na institucionalização de uma política de renda mínima no Brasil. 


\section{REFERÊNCIAS}

BEHRING, Elaine. Brasil em contra-reforma: desestruturação do Estado e perda de direitos. São Paulo: Cortez, 2003.

DRIABE, S.; FONSECA, A; e MONTALI, L. "Programas de renda mínima para famílias carentes: levantamentos das experiências e de avaliação". In: LOBATO, Ana Lúcia (org.) Garantia de renda mínima: ensaios e propostas, Brasília, IPEA, 1998.

DRAIBE, S. As políticas sociais nos anos 90. In: BAUMANN, R. (Org.). Brasil: uma década de transição. Rio de Janeiro: Campus. 1999.

GOIS, Antônio. Estudo propõe universalizar Bolsa-Família. Folha de S.Paulo, São Paulo, 28 nov. 2004. Folha Brasil, Caderno 1.

LAVINAS, Lena; VARSANO, Ricardo. Renda mínima: integrar e universalizar. Novos Estudos Cebrap, São Paulo, n. 49, nov. 1997.

LESBAUPIN, Ivo. O desmonte da nação em dados. Petrópolis, RJ: Vozes, 2002 .

MOTA, Ana Elizabete. Cultura da crise e Seguridade Social: um estudo sobre as tendências da previdência e da assistência social brasileira nos anos 80 e 90. São Paulo: Cortez, 1995.

NETTO, José Paulo. FHC e a política social: um desastre para as massas trabalhadoras. In: LESBAUPIN, Ivo (Org.). O desmonte da nação: balanço do governo FHC. Petrópolis, RJ: Vozes, p. 75-89, 2003.

OLIVEIRA, Francisco de. Prefácio. In: BEHRING, Elaine. Brasil em contrareforma: desestruturação do Estado e perda de direitos. São Paulo: Cortez. 2003.

PEREIRA, Potyara. Necessidades humanas: subsídios à crítica dos mínimos sociais. Sâo Paulo: Cortez, 2000.

POCHMANN, Márcio. Desenvolvimento trabalho e solidariedade. São Paulo: Cortez, 2002.

RAMOS, Carlos Alberto. Programa de garantia de renda. Brasília, DF: IPEA, 1994.

RAMOS, Carlos Alberto; SANTANA, Ricardo. Subsídios para a reformulação do questionário do Cadastro Único. p. 1-40, 2002.

SILVA, Maria Ozanira Silva e. Renda mínima e reestruturação produtiva. São Paulo: Cortez, 1997. 